\title{
Information and Library Studies on a Virtual Campus
}

\section{Rita Marcella and Graeme Baxter}

\section{The authors}

Rita Marcella is Reader/Depute Head of School, School of Information and Media, The Robert Gordon University, Aberdeen, UK. e-mail: r.marcella@rgu.ac.uk

Graeme Baxter is a Research Assistant, School of Information and Media, The Robert Gordon University, Aberdeen, UK. e-mail: g.baxter@rgu.ac.uk

\section{Keywords}

library and information studies, distance learning

\section{Word count $=5,870$ words}

\begin{abstract}
Provides a critical overview of the introduction of the Postgraduate Diploma/Master of Science course in Information and Library Studies, in on-line distance learning mode, by the School of Information and Media at the Robert Gordon University in Aberdeen. Includes some initial observations on the success of the distance learning approach, and on the implications of directing, and interacting with, students by remote, largely electronic means. Student response to the course materials and to the communications media utilised are discussed critically, in particular in terms of interaction, involvement and isolation. Also examines the nature of the status and personal circumstances of the students being attracted by the distance learning mode.
\end{abstract}




\section{INTRODUCTION}

In September 2000, the School of Information and Media at the Robert Gordon University (RGU) in Aberdeen began delivery of its Postgraduate Diploma/Master of Science course in Information and Library Studies on an on-line, distance learning basis. This paper reviews briefly the literature relating to distance learning in library and information studies (LIS), before providing a critical overview of the initial months of operation of the RGU course. It includes some initial observations on the success of the distance learning approach, and on the implications of directing, and interacting with, students by remote, largely electronic means. Student response to the course materials and to the communications media utilised are discussed critically, in particular in terms of interaction, involvement and isolation; while staff attitudes to the shift to a radically different pedagogic style are reviewed. The paper also examines the nature of the status and personal circumstances of the students being attracted by the distance learning mode.

\section{DISTANCE LEARNING IN LIS: A BRIEF LITERATURE REVIEW}

In an historical review of LIS distance education in the United States, Barron (1990) pointed out that, as early as 1888, Melvil Dewey called for the New York State government to develop correspondence courses in special library and small library services. Over one hundred years later, in 1996-97, 75\% of American library schools were offering one or more courses away from the home campus (Chepesiuk, 1998). Barron (1991) posited some relationships between distance learning and library school survival and growth, concluding that it has the potential to make LIS programmes stronger, more visible and more responsive to the profession and to society.

Traditionally, LIS distance learning courses in the USA have been delivered through postal correspondence or by sending faculty, complete with teaching materials, to present programmes at satellite campuses. Since the 1980s, however, an increasing number of LIS courses have been offered using telecommunications technologies. Barron (1996) provided some examples of current uses of technology in American LIS distance education, primarily using audioconferencing and videoconferencing. While Coleman (1996) discussed the results of a survey, conducted in 1993, of 12 American library schools using telecommunications in distance learning courses. While those surveyed believed that such technologies were well suited for delivering LIS teaching, it was felt that instructional delivery using 
telecommunications was more time-consuming than traditional classroom instruction. The survey also found that one of the more positive aspects of using technologies for distance education was felt to be the feedback and interaction among students and faculty.

The literature also contains some detailed case studies of American library schools using technology to deliver distance learning courses. Douglas (1996), for example, reported on the Master LIS programme at the University of South Carolina, where courses are largely televised live through a system of one-way video and two-way audio interaction. While Main (1998) discussed a web-based LIS programme at San Jose State University. Main suggested that such distance education programmes are often seen as separate from campus-based programmes, and argued that all campus-based students should take at least one class in a web-based virtual classroom, thereby training them to think and work in a virtual networked environment.

In the United Kingdom, as MacDougall and Brittain (1993) have noted, opportunities for LIS distance learning have, with one or two exceptions, been less well developed. Indeed, in a 1989 British Library funded survey of distance learning courses (Haythornthwaite and White, 1989; Haythornthwaite, 1990) only eight courses in the UK were identified as being relevant to the needs of librarians or information scientists. A search through the British Association for Information \& Library Education and Research (BAILER) directory of courses, and the Careers and Qualifications pages of the UK Library Association website reveals that just five UK LIS departments currently offer distance learning courses. Since the inception of its Master's Degree in Management of Library and Information services in 1985, the Department of Information and Library Studies at the University of Wales, Aberystwyth, has been at the forefront of LIS distance education in the UK. Edwards et al (1990) provided an account of the formative years of the course; while the largely positive experiences of some of the earliest students (Sherwell, 1986; Lloyd, 1989) and more recent graduates (Gray, 2000) have also been recounted.

The challenges of, and prospects for, LIS distance education in less developed countries have also been discussed. For example, Kanjilal (1999) and Singh (1999) outlined the situation in India; while Nave (1999) described the design and implementation of one programme in Brazil.

A number of authors (for example: Caspers, 1999; Hufford, 2000) have discussed the role of the academic library in supporting distance learners, in terms of: providing remote access to catalogues and bibliographic and full-text databases; dealing with postal and inter-library loan 
requests; providing current awareness and reference and enquiry services; conducting literature searches on behalf of distance learners; and establishing library induction programmes. Cooper (2000) noted that, in the United States at least, library services offered by distance programmes have tended to be minimal in nature; while Gibson et al (1999) suggested that in the United Kingdom, and in particular Scotland, academic libraries have adopted an ad hoc rather than strategic attitude to developing services for distance learners, with little evidence of progress on a practical level.

\section{THE VIRTUAL CAMPUS AT THE ROBERT GORDON UNIVERSITY}

The RGU's Virtual Campus was established in 1999 and hosts a growing number of webbased open and distance learning courses, on topics such as e-business, nursing and publishing. At December 2000, the Campus had over 2,200 registered users, including some from countries as diverse as Azerbaijan, Madagascar and Venezuela.

Courses on the Virtual Campus have a Hypertext Markup Language (HTML) based superstructure (see Figure 1), with the teaching materials, i.e. lectures and accompanying illustrative slides, generally being presented in Portable Document Format (PDF) and PowerPoint format respectively. The teaching materials can be supported by both e-mail and telephone tutorials; while students can also communicate with academic staff and with each other through a series of course- and module-related electronic discussion forums and community groups. The submission of coursework and the provision of marks and feedback are also done electronically. Indeed, the Virtual Campus attempts to recreate the facilities found on a traditional campus and therefore provides other services such as bulletin boards, event calendars, and a 'Campus Cafe' chat room, as well as access to the University library catalogue and a range of online resources relevant to the content of the courses offered. 


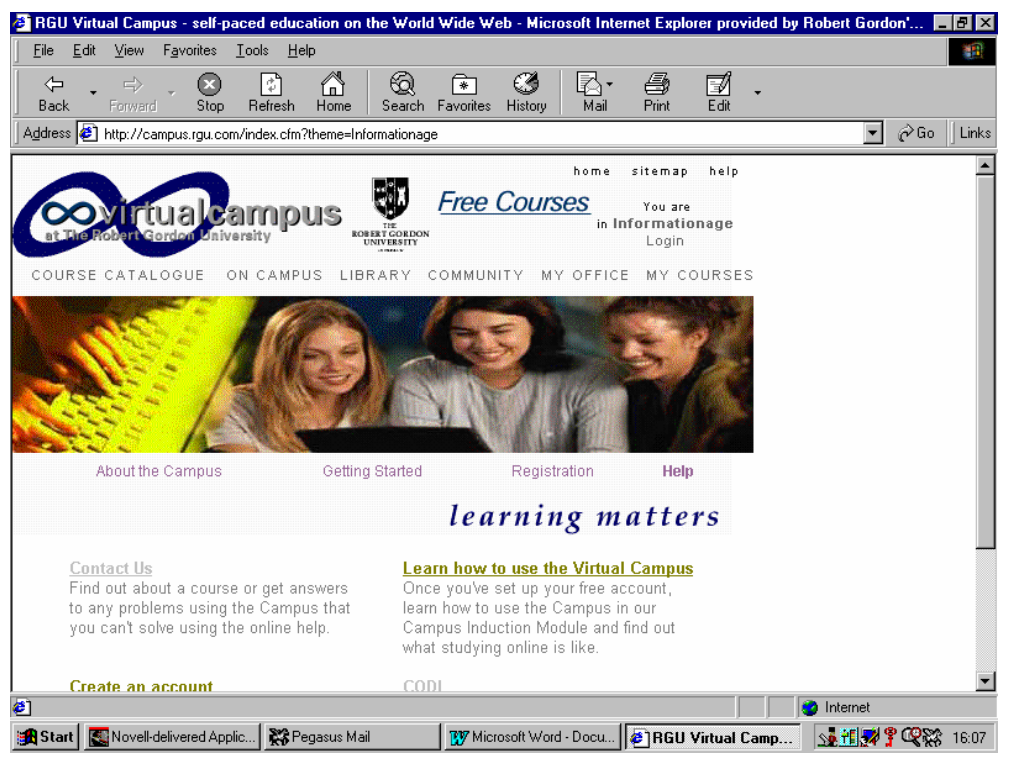

Figure 1: The Robert Gordon University Virtual Campus Home Page

\section{THE POSTGRADUATE DIPLOMA/MASTER OF SCIENCE COURSE IN INFORMATION AND LIBRARY STUDIES}

The School of Information and Media began delivery of its PGDip/MSc course in Information and Library Studies on an online, distance learning basis in September 2000. The Postgraduate Diploma element of the course consists of eight modules:

1. Information Studies

2. Information Management: Policy,

Processes and Use

3. Technical Services

4. Resource Management
5. Subject Specification

6. Reference and Enquiry Services

7. Research Methods

8. Fieldwork Placement

These eight modules can be undertaken through the distance learning mode over a minimum period of two years, with a further year required for completion of a dissertation, leading to the award of Master of Science. The modules are split into topics, with each topic consisting of a text accompanied by illustrative slides, independent learning activities and suggested readings. The subject content of the course is the same as that taught to campus-based students. It has been approved by the Joint Accreditation Board of the Library Association and the Institute of Information Scientists. 


\section{COURSE EVALUATION METHODOLOGY}

As part of the early evaluation of the course, it was felt to be important to determine what the students' objectives in joining the course had been and why they had chosen distance learning as a mode of study, as well as gathering data about their first impressions of the learning environment. In line with the predominant means of staff communications with the cohort, it was decided that an e-mail should be sent to the students asking several questions. The questions are set out below:

- What do you hope to achieve by joining this course?

- How are you coping with distance learning study?

- How do you feel about being a distance student?

- Whether there is any support that you would appreciate at present?

- Whether you have any personal circumstances, which are affecting your studies?

The questions were deliberately very open and sought to mirror the kinds of expansible question that might be used in a face-to-face tutorial to encourage personal discussion of attitudes, feelings and aspirations. The respondents appeared to find the questions clear and intelligible and provided, in the majority of instances, very full, thoughtful and appropriate responses. They were asked subsequently whether they were happy to have their comments used in promoting the course and all agreed, although a small number would not have wished their name to be given in any such use of their responses. The data collection tool, although very simple, was felt to have been successful in gathering valid and reliable data about the students of the course.

The e-mail was sent to the 31 students who had matriculated as distance learning students and who were, therefore, participating in the Virtual Campus. Twenty-nine responses were received, providing an excellent response rate of 93.5\%; however, given the target group it is, perhaps, not unexpected that the survey was so successful. Although some provided very much fuller answers than others, all of the responses were relevant, usable and comprehensible. One student did not tackle all of the questions as set but simply provided some evaluative feedback: this was an exception but the response is included in the discussion below. Each student received a full, individual reply from the Course Leader, discussing any issues raised and responding to queries. It should be borne in mind that the questionnaire was 
disseminated at a very early stage in the programme, that is week five of the course, when students were still finding their way around the campus and the teaching materials.

In analysing the results, each question has been tackled separately with responses being analysed into themes for discussion. The results are discussed fully in the paper that follows and extensive use of direct quotation has been made in an attempt to convey the flavour of the communications that were received. It should be noted that, while students have frequently made evaluative comments as part of other communications with staff, only those comments that were made in response to the questionnaire have been included in this paper.

A second questionnaire was designed to gather data as to academic staff's attitudes to teaching in the virtual environment both in terms of their interaction with students and of their use and application of the technology. It was hoped that this survey would highlight any concerns amongst staff as to the teaching approaches utilised and the pressures of teaching in a new way. A self-completed questionnaire was designed for data collection that utilised a mix of open and closed questions in investigation of aspects such as academic staff's use of a range of functions of the Virtual Campus, their experience in responding to students' need for support and what they had learned from their first experience of teaching on a distance basis.

The questionnaire was disseminated to the 6 members of academic staff that had been involved in teaching the first semester of the course and 3 responses were received. One of the authors, who was very much involved in teaching to the student group, was excluded from this survey and has taken the opportunity of this paper to record some of her personal impressions. Given the very small sample group, the results have not been analysed statistically but are presented in a discursive manner. Generally responses were not very full and it is felt that a less formal means of data collection might have been more revealing.

\section{RESULTS OF THE E-MAIL SURVEY OF STUDENTS}

Of the 29 responses received, 27 were from female and 2 from male respondents. This indicates the overwhelming gender bias amongst the cohort and suggests that there may be greater barriers for women in becoming full time students. Of the total sample, 27 students are in work while 2 are not. Of those that are working, the majority (26) work in libraries or information services. 
Students were initially asked why they had joined the course, as it was felt that this would reveal both their objectives and something about the particular individual circumstances that had led them to seek to study the subject, information and library studies, and in a distance environment. Of the 29 respondents, 28 provided a relevant and meaningful response. A very significant number (12 respondents) talked about the importance of gaining a qualification that was professionally recognised and accredited by the Library Association and the Institute of Information Scientists, in particular emphasising the desirability of attaining chartered status. Similarly a large proportion (14 respondents) felt that successful completion of the course would improve their career prospects and assist their future progression in gaining greater status or a promoted post; additionally two respondents specifically mentioned Continuing Professional Development (CPD). Comments suggested that respondents felt that they were at an impasse professionally at present: 'I have, however, reached a ceiling and I need a professional qualification in order to be able to progress' and 'It's the only way I can enhance my career opportunities'. Six respondents felt the course would help to broaden their career options or increase their future opportunities. One student felt that the Master's level qualification was particularly significant.

Ten students felt that it was important that they add to their often quite considerable experience of working in libraries, a better understanding of the theoretical underpinning in information and library science, making comments such as, 'I hope to get some theoretical underpinning for the things that I am employed to do, e.g. classification' and 'I would like a framework within which I can place my daily work'. In a related response nine individuals expressed their desire to expand or increase their knowledge and understanding of their chosen work environment: 'I hope that the course will provide me with a greater understanding of the job I do.' There was a sense amongst this group of respondents that they wished to gain a sense of personal achievement and some recognition of the validity and significance of their work experience. Only two respondents, who were not presently working in a library, indicated that they wished to obtain vocational training in a new field: this finding is in direct contrast to the pattern for full time students, where far more students have little experience of libraries but wish to enter the vocation. Three respondents were hoping for a change of career direction within librarianship: 'To enable me to make choices about where I want to go next in the profession.'

Fewer students explained why they had sought to join a distance learning course. Of those that did, five stated that they wished to avoid taking a year out of work or a career break: 'I was so pleased to find a course that I could do in my own time but also so relevant to my circumstances'. Two respondents had already completed an open learning first degree and 
were therefore very comfortable with this approach, while another was specifically looking for a flexible approach to learning.

Students were then asked how they were coping with distance learning study and how they felt about studying remotely. It was felt that students were likely to have some anxieties about distance study and that they might be encountering problems in, for example, feeling isolated or in being unable to access resources. In asking students how they were coping with distance learning so far, the authors were asking students to engage in a certain degree of selfevaluation as well as evaluation of the support provided by the course team and the University. Their responses have therefore been grouped into these two broad aspects.

In terms of their self-assessment, respondents were very open and honest in response. A number felt that they could improve their performance, get more involved or increase their activities in some way. In very general terms, 16 respondents described themselves as coping well with the course, while 12 expressed some reservations and one respondent did not reply to the question. No one felt that they were coping badly with the course.

When asked how they felt about studying remotely, a number of students highlighted potential problems but then suggested ways in which they felt these were being overcome. One student, for example, felt that the biggest disadvantage was likely to be the lack of opportunity to discuss problems with peers but then acknowledged that community groups provided a forum for this kind of interaction. In total, seven respondents mentioned potential feelings of isolation. Another student commented that 'the community groups help to counter any feelings of isolation'. Some students were finding the virtual learning environment in itself stimulating: 'I am learning from the environment as well as the content of the course. There is a buzz about the interaction.' In a related response a respondent found the distance approach 'a novel and interesting way to learn'. One student described the virtual campus as 'going a long way toward overcoming the problems of isolation and the uncertainties that I'm sure we all feel when tackling a new subject', while another felt they 'are good ways to keep in touch and not feel too lonely'. Seven students felt that the level of interaction enabled by the virtual campus with academic staff was excellent and compared favourable with prior experience, while three others mentioned that the discussion forums were particularly useful: 'There is a lot more contact on this course with other students than with the OU [Open University]. Also you can contact your tutors whenever you like which is good'. One respondent was 'surprised at how much contact there can be with tutors and other students. It seems that we get more attention than would be possible for students on campus'. One student commented that she had initially been worried about potential isolation but was "not 
anymore!', presumably as a result of her experience on the course. However, some students still missed the chance to meet face-to-face.

Four students praised the structure of the course and its format on the campus. They felt that it had been easy to orient themselves to the arrangement of the teaching materials and the functions that were enabled by the virtual campus. Equal numbers of students in each case (eight) described themselves as having good access to resources and having some difficulty in accessing resources. The questionnaire was disseminated at a point in the course when students were still finding their way around the University Library's gateway to remote resources and when some students had not become proficient in the use of such resources. The survey highlighted the significance, however, of ensuring that student access to library resources be enabled immediately upon their joining the course. It is fair to say that those students who were working in large libraries were very much happier about their ability to access readings and support materials.

Four respondents felt that distance learning was daunting in some respects: 'I tend to assume that everyone is doing far more than I am or is more experienced in the technology side of things through their work, so at this stage I am still a bit anxious.' Two respondents specifically mentioned that they felt overawed or daunted by the quality of some of the input from others in the discussion groups, in particular in relation to the independent learning activities. However, this is not dissimilar to the experience of students in any kind of seminar or discussion group, where some students may dominate the 'conversation': 'I would like to participate more in discussions but I never feel that I have anything worthwhile to add'. Alternatively, some students felt that the independent learning activities were 'an excellent way to learn a subject' and that 'posting my findings brought a definite sense of achievement'. A number of the students who expressed feelings of uncertainty or anxiety, said that these had lessened in the time that they had already spent on the course and they were conscious that they would feel more reassured when they had successfully completed some of the coursework assignments.

Eight respondents felt that the course was very demanding of their time and efforts and that this was particularly so when trying to juggle the required commitment with other work and family pressures. In fact the responses to the survey were particularly instructive for academic staff in this respect, in that they emphasised the extent of the other commitments which students sought to fulfil. A typical response was that of one student who was 'finding the distance course rewarding but tiring'; another described the workload as 'heavy but manageable'. Some students felt that a greater degree of flexibility in completion of the work 
was desirable, although such flexibility would work against the potential for the development of a mutually supportive cohort working through course materials and assessments at the same pace.

Alternatively a significant 11 students enjoyed the flexibility that the course does offer: 'I work best late at night', 'I enjoy being able to log on at all hours and to communicate with others at times suitable to me' and 'I enjoy being able to manage my own time'. They tended to feel that the virtual campus provided them with the tools necessary to work at times and a pace that suited them. Another cited advantage was that studies did not suffer if a student was ill or on holiday: the materials were there for them to engage with on their return. Others found that it fitted in with the demands of work and family.

When asked if there were any forms of additional support that they would find useful, 16 students stated that they either did not require any additional support or that they did not at present require additional support. Thirteen students identified some form of additional support that would have value for them. Two students indicated that evening telephone tutorials would be welcome, and it is now practice for academic staff to offer telephone tutorials in support of submissions at a time that would be most convenient for the individual student. This works fairly well in practice and allows tutorials to be scheduled over a wide time-scale. It is usually a minority of the class that wish an evening tutorial, but in those cases where it is preferred it allows privacy and peace to concentrate on the interchange. Eight students identified access to resources as an area where they required additional support. This has been one of the most challenging areas for course management in that it is clear that students have a very wide variety of experience in terms of their physical access to reading materials. Generally, it appears that distance students are very willing to buy books, in comparison with full-time on-campus students, and that they merit suggested readings that may be purchased online very highly. Despite support from the University Library Service in the form of postal loans, it has also been found useful to ask academic staff to provide guidance on the readings that are available in full-text form electronically via the Internet. Particular use is therefore made by staff of those databases of full-text journal articles to which the University subscribes and the course team are developing use of digitised readings through the copyright clearance process, although there have been some difficulties with publishers refusing to allow digitisation while they are quite comfortable with photocopied materials. This is a challenging area and one where academic staff must reorient their practice specifically to meet the needs of distance students. 
Other forms of support were suggested by individual respondents. One student felt that it would be useful if the class were given a clearer indication of which parts of the course activities were mandatory and which were merely voluntary. This was felt to be particularly significant in light of the visibility of students' contributions to the discussion groups. While emphasising that these were very valuable in terms of learning, it was made clear that such contributions formed no part of the assessment and of the marks gained by students for a particular module. It is interesting to note that contribution to the discussion of individual topics has been highly variable. Some topics have generated a large body of discussion while others have not. It is felt that it is particularly important for academic staff to generate discussion and to respond positively and frequently to the contributions made by the class.

Another student, who was not presently working in a library environment, wished to gain relevant work experience and this possibility was discussed fully with the individual, in particular in terms of the relationship of such experience to the placement module which students complete in the second year of the course. Two students required additional IT support and were directed to the European Computer Driving Licence offered by the University. One student suggested that an integrated work schedule covering two modules would be useful and provided a spreadsheet with this information. The spreadsheet was shared with other students via their own Student Learning Group. However, it is felt that this is not a particularly useful feature as not all students will be taking two modules and, particularly as the course progresses, students will be taking more individual mixes of modules.

The respondents were asked finally whether they had any personal circumstances which were, or might be, affecting their studies. Seventeen students indicated that they were experiencing such 'difficult' personal circumstances, while 11 students were not. Of those that identified personal circumstances, eight indicated that family commitments were a significant factor, while seven mentioned heavy or unusual work circumstances. Many of these faced problems in juggling work, their family and study. Four students indicated that they had health related problems. One student mentioned financial worries and five stated that they had holidays due during the semester. The latter is more frequently a problem than for full-time students who are not expected to schedule holidays in term time. One overseas student had greater difficulty than the other students in accessing printed materials in support of the course.

In addition, seven students took the time to indicate that they had valued the opportunity to make personal contact in the form of the personal e-mail tutorial and thanked staff for their support: 'thank you for asking how I am'. It is felt, therefore, that some such form of 
personal interaction should take place periodically and the interchange should be initiated at an early point in the course of studies.

\section{RESULTS OF THE QUESTIONNAIRE SURVEY OF ACADEMIC STAFF}

Academic staff were initially asked for their most positive and negative experiences in using the Virtual Campus. Staff were in agreement that the most positive aspect to date was the level and standard of communication and interaction with students. Negative comments centred on the time-consuming process of responding to students' individual e-mail enquiries, and on technical problems encountered when sending a large e-mail attachment containing reading material to students - a process that has not been repeated.

Navigation around the Campus was regarded as straightforward, although it was felt that it can be quite easy to 'lose' messages and threads in the discussion forums. Staff had used or closely examined the majority of the Campus' many features, tools and resources. Those regarded as the most useful are: the Campus Profile, where staff and students can introduce themselves and provide details of their professional and personal interests (see Figure 2); the course- and module-related Discussion Forums and Community Groups (see Figure 3); the free Campus Induction Module, which introduces staff and students to the concepts and techniques required to successfully use the Campus; and the Campus Event Calendar. When asked to suggest ways in which the Campus service might be improved, there was general agreement that improved access to readings in electronic form was a major issue, as has been discussed above. One respondent also felt that videoconferencing should be made available in due course. It should perhaps be pointed out here that the Virtual Campus hosts a growing number of presentations (in Real Video Clip format) by visiting speakers. These are on topics such as children's books, copyright and network policy and have been well received by the distance learning students. 


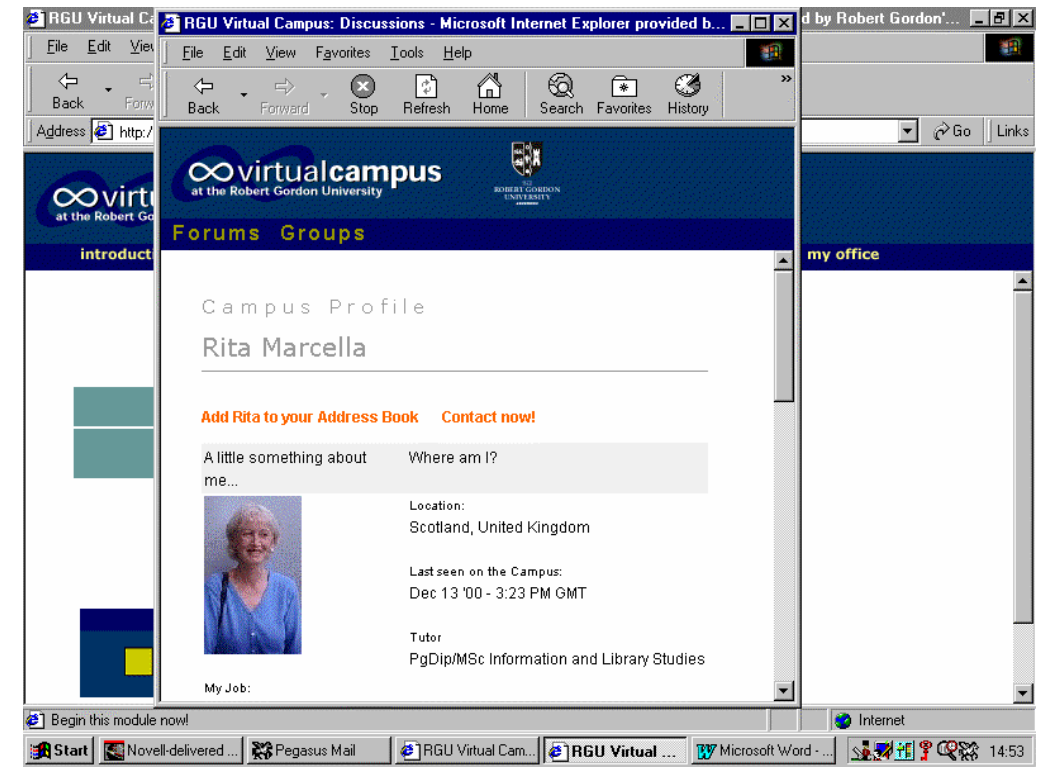

Figure 2: Example of a Campus Profile

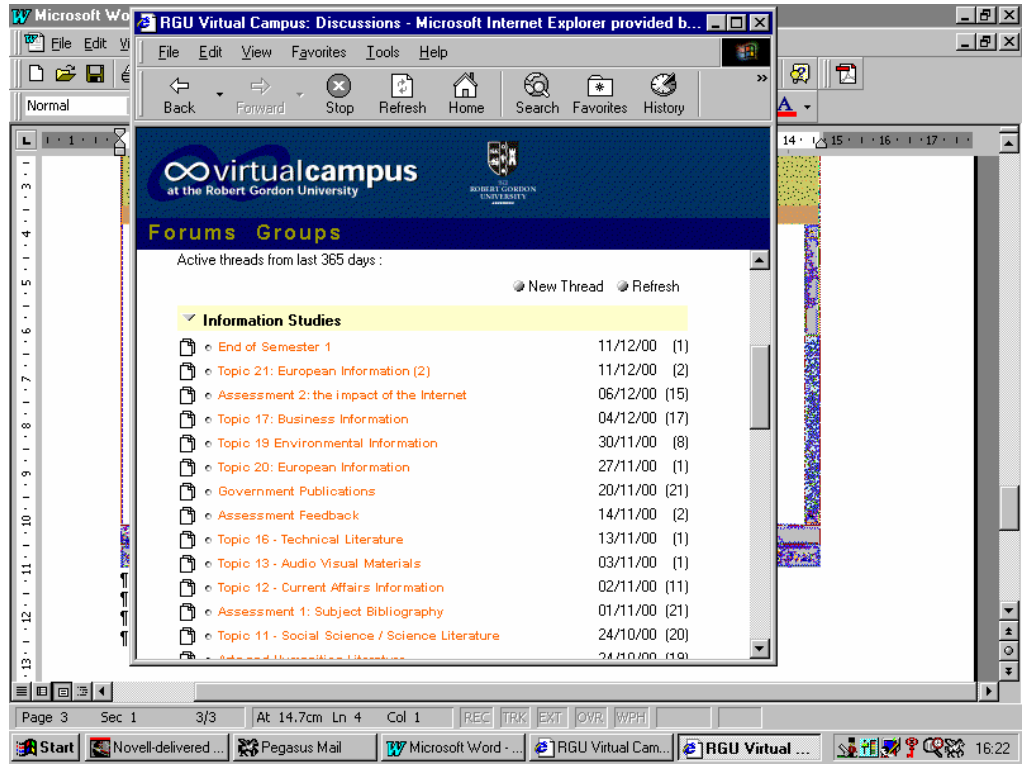

Figure 3: Example of a Discussion Forum 
Staff were asked if their initial experiences with distance learning students might encourage them to change their teaching materials or teaching style for future modules and student intakes. One respondent, having had to deal with several time-consuming e-mail enquiries concerning a particular assignment, indicated that the guidelines for the assignment would be modified to take into account the questions and issues raised. Another staff member indicated that greater consideration would be given to the nature of the independent learning activities associated with particular topics. The issue of providing feedback on draft assignment submissions was also raised: it was suggested that the School should introduce a policy, whereby each student who required such support should be limited to one draft submission per assignment.

Finally, staff were asked about the nature of their interaction with students, and whether this differed from that with on-campus students. Apart from the additional time required to correspond with individual distance learning students by e-mail, it was felt that the two groups of students are quite similar: each contains individuals who are more 'vocal' than others, who lead discussions and who interact more freely with teaching staff; while each group also contains students who do not contribute to discussions and who ask for or require little or no further explanation or support. One respondent was also of the impression that the distance learning students expect an immediate response to their enquiries.

\section{CONCLUSIONS}

The e-mail questionnaire to students was found to be a valid method of data collection that gathered extensive information about the respondents and their attitudes. It was also found to be a welcome form of interaction by a number of respondents and would, therefore, be repeated with future cohorts.

Respondents had largely joined the MSc in Information and Library Studies by distance learning in order to gain a professionally accredited qualification that would improve their career prospects and allow them to progress beyond a currently encountered ceiling in the attainment of promotional objectives. A very significant number also felt that the qualification would enable recognition of their often very considerable body of work 
experience, while providing them with the theoretical underpinning for the work in which they were engaged. Far fewer than for full-time students felt that the course would give them vocational training in order to move into a new professional field. Distance learning had appealed to respondents who did not wish to take a career break or whose personal circumstances prevented full-time study away from home.

Most of the students felt that they were coping well in the distance learning environment. Isolation emerged as a significant potential problem, although the majority felt that the University's Virtual Campus features, with its discussion groups and potential for individual as well as group communication, had helped to overcome any such 'loneliness'. Generally respondents were very happy with the level and nature of interaction and many felt that it compared favourably with prior educational experience. The most significant problem to emerge was that of student access to resources. This area was one that had raised a good deal of discussion between staff and students. It has been necessary for staff to reconsider the ways in which they typically approach the guidance of distance students to additional reading materials and to emphasise the availability of materials electronically. The course team hope to build a collection of readings in electronic form, either via access to databases of electronic journals or via the digitisation of texts for students, for future use. These findings would support the view that academic libraries must take a strategic attitude to the delivery of services to distance learners, in line with Gibson et al (1999).

Some students expressed feelings of anxiety or that that they found study 'daunting' in some respect. While this is not an uncommon feeling amongst full-time on-campus students, it is recognised that distance students require reassurance and guidance at an early stage in their study in order to help them to appreciate the extent and scale of the effort expected of them and the 'manageability' or 'achievability' of the course. This might be accomplished by a greater level of discussion of the staff's awareness of the problems faced by distance students and, with future cohorts, by provision of statistics relating to past students' pass rates. Simply to be able to show that former students have coped can be immensely reassuring for current students.

Responses do illustrate very graphically the extent to which students are juggling with work, family and study commitments and are therefore highly illuminating for staff in seeking to respond to students' personal circumstances. The majority of students valued the flexibility that the course offered and this was clearly a significant factor for them. It was felt that this flexibility allowed them to cope with the high level of demands that were placed upon them. The additional support required by respondents focused largely on access to resources, as 
previously indicated: however, there were some concerns about the 'visibility' of students' contributions to class discussions. The scale of significant personal circumstances would appear to be greater and more frequent than for full-time students and the course team must be conscious of this aspect of distance learners' personal lives in developing interactions with them and in guiding them through the process of learning.

Academic staff felt that the standard and quality of communications with students via the Virtual Campus was very high. They were aware of the problems associated with access to sources for students and had learned a number of lessons from the first experience of distance learning. Apart from high expectations in terms of speed of response to e-mails, there was no sense that the distance students differed materially from those on campus.

Academic staff agree that distance delivery of LIS education using telecommunications (i.e. the Internet in this instance) is more time-consuming than classroom instruction, in particular in responding to e-mail communications. It must also be acknowledged that a good deal of resources and effort have gone into the conversion of the course into electronic form. While there are differences between the virtual and physical classroom, the authors would agree with Main (1998) that all students should engage in learning in at least one module in a virtual networked environment, in order to experience the interchange and communication of knowledge that is enabled in such an environment. In a related development of an Intranet for on-campus students, the authors have found that this technology is impacting materially upon all forms of interaction with students. 


\section{REFERENCES}

Barron, D.D. (1990) "The use of distance education in United States library and information science: history and current perspectives", Education for Information, No 8, pp.325-339

Barron, D.D. (1991) "Distance education and the closing of the American library school", Library Quarterly, Vol 61 No 3, pp.273-282

Barron, D.D. (1996) "Distance education in North American library and information science education: applications of technology and commitment", Journal of the American Society for Information Science, Vol 47 No 11, pp.805-810

British Association for Information \& Library Education and Research (1999), Directory of courses in library and information studies in the U.K. and Ireland 1999/2000. Available at http://www.bailer.ac.uk/directory.pdf [Accessed December 2000]

Caspers, J.S. (1999) "Outreach to distance learners: when the distance education instructor sends students to the library, where do they go?", The Reference Librarian, No 67/68, pp.299311

Chepesiuk, R. (1998) "Learning without walls", American Libraries, Vol 29 No 9, pp.62-65

Coleman, A. (1996) "Public performances and private acts", Journal of Education for Library and Information Science, Vol 37 No 4, pp.325-342

Cooper, J.L. (2000) "A model for library support of distance education in the USA", Interlending \& Document Supply, Vol 28 No 3, pp.123-131

Douglas (1996) "MLIS distance education at the University of South Carolina: report of a case study", Journal of the American Society for Information Science, Vol 47 No 11, pp.875879

Edwards, R.J., Roberts, D.H.E. and Tunley, M.F. (1990) "Aberystwyth - at a distance", Education for Information, No 8, pp.341-348 
Gibson, A., Newton, R. and Dixon, D. (1999) "Supporting open and distance learners: practice and policy across further and higher education libraries", Library Review, Vol 48 No 5, pp.219-231

Gray, S. (2000) "Talking about a revolution", Library Association Record, Vol 102 No 12, p.701

Haythornthwaite, J.A. and White, F.C.P. (1989), Distance education in library and information studies, British Library Research Paper No 50, British Library Research and Development Department, London.

Haythornthwaite, J. (1990), "Distance education and the information scientist", Aslib Proceedings, Vol 42 No 1, pp.31-39

Hufford, J.R. (2000), “The university library's role in planning a successful distance learning program", The Reference Librarian, No 69/70, pp.193-204

Kanjilal, U. (1999), "Education and training of library and information science professionals through distance mode: challenges for the Indira Gandhi National Open University in the next millennium”, FID Review, Vol 1 No 2/3, pp.44-49

Library Association (2000), Careers and qualifications: where to study in the UK. Available at http://www.la-hq.org.uk/directory/careers/where.html [Accessed December 2000]

Lloyd, I. (1989) “A personal view of studying at a distance”, Scottish Libraries, No 17, p.8

MacDougall, J.J. and Brittain, J.M. (1993), "Library and information science education in the United Kingdom", in Annual review of information science and technology, Learned Information, Medford, N.J., pp.361-390

Main, L. (1998) "Web-based virtual classrooms: a model for LIS education", Education for Information, No 16, pp.333-340

Naves, C. (1999) "Distance education and information science in Brazil", FID Review, Vol 1 No 2/3, pp.39-43 
Sherwell, J. (1986) "Professional education by distance learning: experience of the master's degree at CLW", Library Association Record, Vol 88 No 11, p.544

Singh, J. (1999) "Library and information science distance education in India: problems and prospects”, FID Review, Vol 1 No 2/3, pp.25-29 